\section{A derivação regressiva verbal em língua portuguesa segundo a tradição filológico- gramatical*}

The verbal backformation in Portuguese language according to the philologicalgrammatical tradition

João Batista Costa GONÇALVES (UECE) jbcgon@ig.com.br/joao.goncalves@uece.br

Recebido em: 11 de abr. de 2019. Aceito em: 03 de out. de 2019.

*Este artigo foi retirado, com algumas modificações, do segundo capítulo da minha dissertação intitulada "Para uma abordagem da chamada derivação regressiva em português", defendida em 16 de outubro de 1998, no Programa de Pós-Graduação em Linguística (PPGL) da Universidade Federal do Ceará (UFC). Esta dissertação foi orientada pelo Professor Dr. Paulo Mosânio Teixeira Duarte (in memoriam), a quem sempre serei sempre grato por ter cooperado grandemente para minha formação acadêmica, profissional e pessoal.
GONÇALVES, João Batista Costa. A derivação regressiva verbal em língua portuguesa segundo a tradição filológico-gramatical. Entrepalavras Fortaleza, v. 10, n. esp., p. 32-48, ago/2020. DOI: $10.22168 / 2237-6321-$ 8 esp1702.

Resumo: É propósito deste artigo organizar, de modo crítico, uma síntese sobre a chamada derivação regressiva em língua portuguesa de acordo com a tradição filológico-gramatical. A fim de apresentar, metodologicamente, uma exposição clara sobre o tema, mostraremos as várias formas como este fenômeno da morfologia derivacional foi encarado sob esta perspectiva de estudos. Do repasse histórico-crítico sobre a derivação regressiva verbal, podemos destacar algumas conclusões a que a pesquisa chegou, como, por exemplo, a tendência de, na tradição dos estudos filológicos-gramaticais, se acatar o nome como derivado e o verbo como derivante em pares como caçar/caça, fugir/fuga e escolha/escolher, sobretudo levando em conta dois critérios: a redução do corpo fonológico do vocábulo e a interpretação do nome como um substantivo abstrato de ação como derivado e o verbo como derivante.

Palavras-chave: Derivação regressiva verbal. Tradição filológico-gramatical. Síntese crítica. 
Abstract: It is the purpose of this article to organize, in a critical way, a synthesis on the socalled verbal backformation in Portuguese language according to the philological-grammatical tradition. In order to present, methodologically, a clear exposition on the theme, we will show the various ways in which this phenomenon of derivational morphology was viewed from this perspective of studies. From the historical-critical review of the verbal regression, we can highlight some conclusions that the research has reached, such as the tendency, in the tradition of philological-grammatical studies, to accept the name as derivative and the verb as derivant in pairs such as caçar/caça, fugir/fuga e escolha/escolher, especially considering two criteria: reduction of the phonological body of the word and the interpretation of the name as an abstract noun of action as derived and the verb as derivant.

Keywords: Verbal backformation. Philological-grammatical tradition. Critical synythesis.

\section{Introdução}

Em morfologia, a chamada derivação regressiva verbal tem sido, no curso das pesquisas filológico-gramaticais e linguísticas, alvo de contravertidas discussões. Para constatar esse fato, podemos mencionar, por exemplo, as diversas terminologias usadas para tratar formas como luta e pesca: temos nomes pós-verbais, nomes deverbais, formas regressivas, formas normalizadas ou ainda nominalização. Além da confusão terminológica, que, a princípio, pode parecer uma função perfunctória, há outros pontos relevantes a salientar como a direcionalidade do processo derivacional: a forma nominal deriva do verbo ou o origina?

Justifica-se, pois, o presente trabalho como uma pesquisa de caráter eminentemente teórico que pretende, numa atitude crítica de análise, examinar a chamada derivação regressiva verbal em português nos compêndios de filologia e gramática.

Frente a estas questões, o objetivo deste artigo é, assim, traçar um panorama histórico-crítico das inúmeras abordagens que a chamada derivação regressiva verbal recebeu, no âmbito da tradição filológicogramatical, em língua portuguesa.

Para efeito de organização, trataremos da derivação regressiva verbal dividida em quatro tópicos distintos, conforme o enfoque dado ao tema pelos filólogos e gramáticos, quais sejam: 1) derivação regressiva verbal como um tipo dos nomes deverbais; 2) derivação regressiva verbal como um subtipo da chamada derivação imprópria; 3) derivação regressiva verbal como uma derivação progressiva; 4) derivação regressiva verbal como um processo subtrativo e analógico.

É preciso assinalar que essas séries não constituem grupos rígidos. A divisão das seções, por vezes, pode ser fronteiriça, a depender do ângulo da proposta que se está privilegiando. O critério que norteou nossa divisão foi o que é mais específico da abordagem de cada autor. 
10 (esp.)

$32-48$

ago.

2020

\section{Derivação regressiva verbal}

Derivação regressiva verbal como um tipo dos nomes deverbais

Fernão de Oliveira (1975), embora de forma bastante incipiente, fez menção dos derivados regressivos, arrolando-os sob a expressão genérica nomes verbais ${ }^{1}$. É o que se pode depreender da seguinte citação do gramático português: "[...] e os nomes verbais: assim também são diferentes: porque de ler dizemos lição: e de orar oração: mas de amar e honrar dizem amor e honra." (OLIVEIRA, 1975, p. 87)

É fácil perceber que, para o gramático, nos nomes verbais, estão englobados os derivados sufixais (ler/lição, orar/oração) e os derivados regressivos (honrar/honra).

Proposta semelhante segue João de Barros (1957), com a ressalva de que, na sua abordagem, a distribuição dos substantivos deverbais é bem diferenciada. Ainda sob a rubrica nomes verbais, engloba o que hoje denominamos:

a) derivados sufixais: amor/amar (se bem que o exemplo é questionável, pois parece tratar-se na verdade de dois vocábulos com entradas independentes ligadas à raiz am-);

b) derivados regressivos: suspiro (suspirar), choro (chorar) (o autor não atentou para alternância vocálica / つ / /o / no par chorar/choro, presente ainda em grupos como sufocar/ sofoco, rogar/rogo etc., o que o distingue de suspirar/ suspiro, em que não há o fenômeno da metafonia);

c) derivados impróprios por substantivação do infinitivo: Depois que olhei o triste viver = Depois que olhei a triste vida (o gramático não atentou para a distinção semântica entre viver substantivado e vida).

Pode-se perceber que, diferentemente de Fernão de Oliveira, João de Barros incluiu, no que ele denomina de nomes verbais, a chamada derivação imprópria.

Na esteira de João de Barros, Júlio Ribeiro (1911) continua a encampar a derivação regressiva entre os nomes verbais. Na parte em que dedica à formação de palavras, o gramático abre uma seção para tratar do que chama substantivos derivados de verbos. Segundo o

\footnotetext{
${ }^{1}$ A despeito de uma questão terminológica, Michel Bréal (apud BARRETO, 1980), ao invés de nomes ou substantivos verbais, preferiu, segundo Barreto (1980), chamar esses nomes de pós-verbais, inaugurando, assim, o termo num ensaio publicado em 1881, por lhe parecer mais adequado para esses nomes derivados de verbos.
} 
autor, há três modos, em língua portuguesa, de se formar substantivos a partir de verbos:

1) através de sufixação: andança, fixação;

2) através do emprego da $3^{\text {a }}$ pessoa do singular do indicativo presente, da $1^{\mathrm{a}}$ e $2^{\mathrm{a}}$ conjugação: a apanha da azeitona - a malha do centeio; os comes e bebes - os pertences;

3) através do emprego do infinitivo presente (o comer, o dormir), do particípio presente (negociante, amante) e do que o gramático chama de particípio aoristo (vista, queimada).

Como se pode observar, há certos pontos de contato entre a tipologia dos deverbais de Júlio Ribeiro e a que propôs João de Barros. Ressalte-se, porém, que os exemplos dados para os tipos de deverbais sufixais em Júlio Ribeiro são mais adequados, porque os sufixos anexados à base são facilmente detectáveis (and-ança, fix-ação). Salientem-se, todavia, algumas diferenças: a inclusão das chamadas formas participiais e a ressalva de que existem deverbais ligados à primeira pessoa do singular ou à terceira do singular. Entretanto, para este último caso, como se explicariam os casos com diferença no timbre da vogal (contorno, consolo), para não mencionar outros exemplos como escolha e destaque que não se relacionam com a $3^{\mathrm{a}}$ pessoa do singular do indicativo presente? Assinale-se ainda que a linha que separa o segundo do terceiro tipo parece ser tênue, pois, em ambos os casos, ocorre a substantivação de formas verbais pela anteposição do artigo. Na seção que segue, discutiremos sobre esse tópico com maior detalhamento.

Derivação regressiva verbal como subtipo da chamada derivação imprópria

Filólogos e gramáticos houve que trataram os regressivos verbais como um caso de derivação imprópria, a exemplo de Silva Júnior e Andrade (1894), Maciel (1910), Gomes (1913), João Ribeiro (1933), Nunes (1956), Pereira (1958) Michaëlis Vasconcelos (s/d) e Azevedo Filho (1971) que analisaram a derivação regressiva como a passagem do verbo para o substantivo, ou seja, a substantivação da $1^{\mathrm{a}}$ ou $3^{\mathrm{a}}$ pessoa do singular do presente do indicativo (combate, prova) e/ou da $1^{\mathrm{a}}$ pessoa do singular do subjuntivo (venda, alcance). ${ }^{2}$ Jucá Filho (1945), porém,

${ }^{2}$ Poder-se-ia tentar corroborar essa ideia, argumentando que, muitas vezes, o falante comum tende a dizer perca ( $3^{\mathrm{a}}$ pessoa do presente do subjuntivo), ao invés de perda, ao referir-se ao ato de perder. 
10 (esp.)

$32-48$

ago.

2020

já nos chama a atenção para a necessidade de se diferenciar entre deverbais regressivos e formas verbais usadas substantivamente. ${ }^{3}$

Vale ressaltar que, ao considerar a derivação regressiva como um subtipo dos derivados impróprios, a maioria dos autores retromencionados utiliza a nomenclatura derivação imprópria, para contrastar com a derivação própria em que se dá pela adjunção de afixos, exceção feita a Maciel (op. cit.), que denominou o processo de derivação inorgânica, contrapondo-a à derivação orgânica, feita por sufixo.

No tocante à precedência das bases, Nunes (1956) observa, partindo de um estudo diacrônico sobre os deverbais regressivos ou substantivos tirados de verbos, para ser fiel à nomenclatura do autor, que determinados substantivos em latim procedem da $1^{\mathrm{a}}$ e $3^{\mathrm{a}}$ pessoas do singular do indicativo de verbos da primeira conjugação e, eventualmente, da segunda e da terceira (lucta, fuga, offensa), 4 ocorrendo semelhante processo em português. ${ }^{5}$ Camara Jr. (1981 - cf. verbete derivação deverbal) informa-nos de que este tipo de formação já existia realmente na língua latina (fábrica > fabrica, de fabricare). ${ }^{6}$

Michaëlis Vasconcelos (s/d), embora seja concorde em incluir a derivação regressiva entre os tipos de derivados impróprios, rejeita a

\footnotetext{
${ }^{3}$ Aguiar (1955), embora não faça a inclusão da derivação regressiva verbal entre os derivados impróprios, acredita, como a maioria dos autores supramencionados, que os deverbais regressivos foram formados das pessoas do verbo. O autor batizou os regressivos como um todo de rederivação, dividindo-os em derivação regressiva (denominais) e derivação temática (deverbais). Para este último caso, sua formação se daria, segundo o autor, com o apoio na $3^{\mathrm{a}}$ pessoa do singular do indicativo presente e na $1^{\mathrm{a}}$ pessoa do mesmo tempo do conjuntivo (subjuntivo) presente, conforme o esquema: batalha $=$ batalha, livre = livrar. Nesta proposta, seria importante examinar, além da questão de saber se estes nomes procedem realmente das terminações verbais, se a nomenclatura é válida como é para o termo recomposição que, associado à composição, "ocorre quando apenas uma parte do composto passa a valer pelo todo e depois se liga a outra base, produzindo uma nova palavra" (MONTEIRO,1986, p. 170).

4 Maurer Jr. (1959) confirma a hipótese de que, em latim, este processo de derivação era formado sobretudo com os verbos em -are: planta (plantare), serra (serrare), cursus (cursare) etc. Michaëlis Vasconcelos (s/d) aceita firmemente esta ideia, chegando mesmo a transpor esta regra para o português, ao afirmar que casos como venda e perda, na nossa língua, vindos de verbos da $2^{\mathrm{a}}$ conjugação, não são substantivos regressivos verbais, mas particípios contraídos, a partir de vendita, perdita.

${ }^{5}$ Egger (apud GAMARSKI, 1988), estudando este tipo de substantivo em francês, já os havia tratado como nomes derivados do radical, através das pessoas do singular do presente do indicativo, numa espécie de formação por apócope do infinitivo.
}

${ }^{6}$ Kehdi (1995) rejeita a interpretação de que formas como fábrica > fabrica sejam tomados como regressivos, pois não houve redução de nenhum elemento formal. Acrescenta ainda o fato de que pós-verbais formados por alternância acentual são de formação erudita e, por isso mesmo, formados tardiamente em nossa língua, o que pode ser confirmado pela não alteração das vogais -ǐ- e -ŭ- de penúltima sílaba e pela própria datação correspondente: fábrica (séc. XIV) $<$ fabrǐca. 
ideia de que esses substantivos verbais tenham vindo das pessoas do verbo, mas do tema verbal puro. Vasconcelos (apud KEHDI (1995)) é deste mesmo parecer. A essa conclusão chegou o autor quando analisou os deverbais regressivos que mantinham ligação com as formas do singular do presente do indicativo românico. Segundo a análise de Vasconcelos, certos substantivos, como erro e rogo, apresentam vogal tônica fechada, se se contrapõem às formas verbais a que elas correspondem. Kehdi (1995) observa que fatos referentes à metafonia invalidam a proposta de Vasconcelos, pois este esqueceu que:

[...] a extensão e a importância da metafonia em português: as vogais a e o influenciam no timbre de $-\mathbf{e}-\mathrm{e}-\mathbf{0}-(-\mathbf{a}$ contribui para a abertura; -o ; para o fechamento da vogal (tônica)). Entretanto, na primeira conjugação, as vogais tônicas -e e -o (procedentes de -e e -o) mantiveram-se abertas em virtude da analogia com a segunda e terceira pessoa do singular e a terceira do plural: rogo > rOgo (por influência de rOgas, rOga, rOgam). Como o substantivo se integra noutro paradigma, pôde ocorrer a metafonia. (KEHDI, 1995, p. 423)

Mostrada a derivação regressiva verbal como subtipo da chamada derivação imprópria no âmbito dos estudos filológicogramaticais, passemos agora à próxima seção.

Derivação regressiva verbal como uma derivação sufixal

Adota Huber (1986) o ponto de vista da derivação regressiva como derivação sufixal, porém sob uma ótica diacrônica. O autor, ao estudar a derivação por meio de sufixos de vocábulos portugueses, separou-a em: derivados por sufixos átonos e derivados por sufixos acentuados. Estes dizem respeito ao processo de sufixação que normalmente se conhece (aça, -aço > -acia, -aciu: ameaça, pedaço). Os derivados por sufixos átonos são os usados para a formação dos pós-verbais (erro/errar, esforço/esforçar). Conforme ainda Huber, como o acréscimo dessas vogais implica mudança gramatical, nada mais razoável do que ver aí uma derivação sufixal. Essa ideia apenas corrobora a posição já defendida por Meyer-Lübke (1923) e Pidal (1958).

Sob um enfoque sincrônico, Luft (apud AKELE, 1988) encarou também estes tipos deverbais como um caso de derivação progressiva e não mais como derivados progressivos. No entender do gramático, há nesse processo derivacional um sufixo derivativo verbal indicador das conjugações que passa a sufixo derivativo nominal de gênero. De acordo com Luft, este tipo de derivação seria explicado por regras 
V. 10 (esp.)

$32-48$

ago.

2020

morfológicas de apagamento e assimilação. Assim, se se têm duas vogais semelhantes, uma é apagada, se as vogais são diferentes, uma assimila a outra, conforme se pode observar nos exemplos mostrados pelo gramático através de esquemas arbóreos:

Figura 1 - Esquema arbóreo dos derivados regressivos
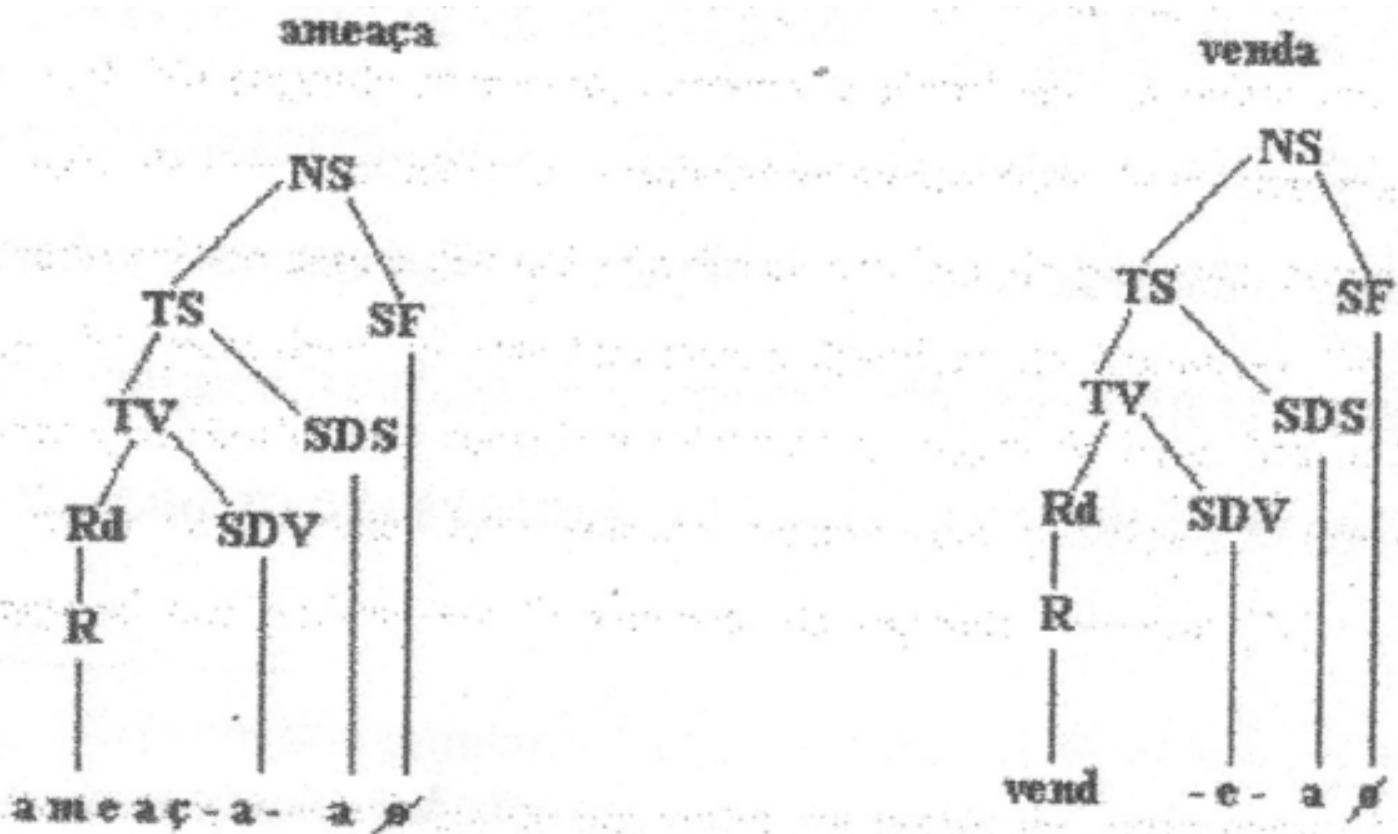

Fonte: Akele (1988).

Em que pese a proposta de Luft em observar que, nos deverbais portugueses, não ocorre uma simples supressão da parte do verbo, uma vez que há o acréscimo, em muitos casos, de uma nova vogal ao radical verbal, as regras estipuladas pelo gramático não explicam como tratar nomes com alternância vocálica (choro/chorar) e/ou deslocamento de acento de acento (renúncia/ renunciar). Ademais não toca no problema essencial da precedência das bases.

Quanto à afirmação de que as vogais finais desses nomes constituem sufixo derivativo nominal de gênero ${ }^{7}$, é válido observar o que Kehdi (1995) assinala a este respeito:

Cumpre, porém, salientar que a existência de numerosos pósverbais em -e nos impede ver aí, desinências de gênero; assinalese, ainda, que em alguns pares em que o primeiro membro termina em -e (sempre masculino), o segundo apresenta ora -o, ora -a: decalque-e/decalc-o, desmam-e/desmam-a. Pode-se, portanto, afirmar que a noção de gênero se acrescenta ao valor sufixal, básico, desses elementos finais. (KEHDI, 1995, p. 424)

${ }^{7}$ Diez (apud GAMARSKI, 1988), um dos primeiros a estudar sobre os deverbais regressivos, viu também nestes derivados verbais uma simples adição de uma terminação de gênero ao radical. 
O autor ainda acrescenta que

Restaria a possibilidade de classificação dessas vogais como temáticas nominais. Assinale-se, todavia, que as vogais temáticas nominais, em primeiro, estão dissociadas da noção de gênero (cf. trib-o (fem), mas-a (masc), font-e (fem), mont-e (masc), o que elimina para o caso que nos interessa, essa possibilidade de classificação. (KEHDI, 1995, p. 424)

Derivação regressiva verbal como um processo subtrativo e analógico

Para Barreto (1980), a derivação regressiva é um processo de formação de palavras que se dá através da supressão, ao invés de acréscimo, de elementos formadores. Daí o autor denominar também este fenômeno como derivação retrógrada e derivação em sentido inverso. Segundo Barreto, as formações regressivas podem ser explicadas pelo que o autor chama de formação profissional. Em outras palavras, o autor é da opinião de que é processo analógico o principal responsável por esta espécie anormal de derivação.

Cabe-nos perguntar, no que diz respeito à definição de Barreto, se a derivação regressiva é sempre uma mera redução formal, ou se há outras implicações, como a alternância de acento, a exemplo de jogo/jogar. A este propósito, convém sublinhar outra vez com Kehdi (1995):

É curioso que nossas gramáticas, no sentido do processo de derivação regressiva, praticamente não fazem referência à metafonia, que é frequente na evolução da língua portuguesa e explica numerosos casos de alternância vocálica no quadro das flexões nominal e verbal. (KEHDI, 1995, p. 423)

Há uma questão a se relevar com respeito ao termo analogia, usado por Barreto para explicar a derivação regressiva. Não existem dúvidas de que formações regressivas são analógicas, mas, como asseveram Basílio (1980) e Gamarski (1988), o termo não se mostra adequado à análise e descrição do fenômeno por ser ainda muito vago. A analogia, por exemplo, não permitiria revelar fatores importantes incluídos no processo, como em estabelecer uma distinção entre problemas relacionados à produtividade dos processos de formação de palavras do léxico, não explicando, portanto, satisfatoriamente a derivação regressiva. ${ }^{8}$

\footnotetext{
${ }^{8}$ Mesmo linguistas privilegiaram o aspecto analógico da formação vocabular para a caracterização dos derivados regressivos, a exemplo de Bloomfield (1984), Hockett (1958) e Pei e Gaynor (1965).
} 
10 (esp.)

$32-48$

ago.

2020

Algo ainda a suscitar questionamentos é a referência do autor à derivação regressiva como espécie anormal de formação de palavras. $\mathrm{O}$ gramático não explicita a que se deve tal anormalidade, se pelo motivo dos regressivos se formarem sem auxílio de afixos ou se por eles não constituírem um processo produtivo na língua.

Já no segundo volume de De Gramática e de Linguagem, Barreto (1982), refletindo sobre a dificuldade em se saber se é o substantivo que provém do verbo ou se é este que deriva aquele, estabeleceu um critério prático para a direcionalidade do processo. Segundo o autor, "se o substantivo denota ação, será palavra derivada, e o verbo palavra primitiva, se o nome denota algum objeto ou substância, se verificará ao contrário." (op. cit., p. 247)

Assim, pesca, porque é nome abstrato deriva-se de pescar, mas telefone, porque é nome concreto, dá origem a telefonar.

Essa distinção, segundo Monteiro (1978) e Gamarski (1988), parece inoperante, pois substantivos abstratos facilmente se transformam em concretos. Dessa forma, tem-se assobio que tanto pode ser a ação de assobiar, como o instrumento com que se assobia. Cabe assinalar que Barreto (1982) havia atentado para essa questão, embora não a tenha aprofundado. São suas as palavras: "Cria é posverbal de criar, mas, concretizado, significa o animal enquanto se está criando: a cria de ovelha." (op. cit., p. 331)

Não obstante, Gamarski (1988) procura ainda mostrar a ineficácia do critério para a identificação de um derivado regressivo proposto por Barreto, argumentando que:

\begin{abstract}
Na medida em que se reconhece que regressivos e sufixais derivados de verbos de ação podem apresentar tanto interpretação verbal quanto nominal com possibilidades de sofrerem expansão para um significado de resultado concreto de ação (crítica, confissão, oferta, etc.). Além disso, há nomes deverbais, sufixais ou regressivos, cujas bases não são verbos de ação; só apresentam interpretação nominal, não denotando, portanto, ação (desejo, aspiração, perda, acontecimento, etc.). Como não se trata de casos isolados, mas de propriedades dos nomes deverbais - no que a rotulação tem de abrangente - o critério fica comprometido. (GAMARSKI, 1988, p. 44-45)
\end{abstract}

Mas, levando em consideração o caso de nomes com capacidade para duas leituras ou só com uma interpretação nominal, somente aqueles que expressassem uma interpretação com ação poderiam ser considerados deverbais regressivos. Assim, o nome conserva seria um derivado regressivo quando entendido como ato de conservar (substituível aqui por conservação); seria primitivo quando interpretado como um objeto, um certo tipo de alimento. A respeito de uma análise dessa natureza, Lobato (1995) ressalta: 
[...] para exemplos como venda, jogo e crítica, em que temos ambigüidade entre uma interpretação como objeto e outra como ação, teríamos de fazer corresponder duas derivações uma em que o substantivo seria a forma primiriva, e a outra em que seria a forma derivada. Do ponto de vista dos substantivos, esse tratamento poderia até ser interessante, pois explicaria tais ambigüidades. Note-se que a ambigüidade nas seqüências em que ocorrem, como é o caso da seqüência 0 jogo do Thiago não durou muito: num dos seus sentidos, essa seqüência pode ser parafraseada como Thiago não demorou muito jogando, e jogo corresponderia a deverbal, mas no outro sentido, em que jogo se refere a um tipo determinado de brinquedo (jogo de damas, jogo de xadrez, etc.), não aceita essa paráfrase, e jogo corresponderia então a um nome básico (cf. Basílio 1987: 42). Mas do ponto de vista dos verbos correspondentes tal tratamento seria inadequado: sem que sejam ambíguos, a ele corresponderiam duas derivações uma como derivados e outra como primitivos. (LOBATO, 1995, p. 207-8)

Seja como for, o método prático de se saber o que deu origem a que para caso dos nomes relacionados a verbos deixa problemas semânticos que dificultarão a descrição do processo derivacional em foco.

Um tratamento para derivação regressiva bastante semelhante ao de Barreto é o de Bueno (1958) e Said Ali (1964). Com estes autores, os regressivos ainda serão vistos como a retirada de um elemento subtrativo decorrentes de uma analogia; é o que se pode depreender das definições para derivação regressiva dos autores supramencionados:

aquela palavra que de outra provém, parecendo, entretanto, que ela seja primitiva e não derivada (BUENO, 1958, p. 112);

[...] dá-se um erro de raciocínio - o termo pré-existente é realmente primitivo mas produz a impressão de ser derivado por sua semelhança com vocábulos que, por sua vez, são derivados (SAID ALI, 1964, p. 256 - 7)

Neste sentido, as críticas feitas a Barreto podem ser estendidas a Bueno e a Said Ali. Falemos deste último.

Como se pode notar acima, a definição do autor apela para termos impressionísticos e psicologicistas, como erro de raciocínio e impressão, derivando, assim, para uma definição pouco objetiva.

Convém observar, todavia, alguns pontos de destaque na proposta de Said Ali. Primeiro, o autor já antevê a alta produtividade dos regressivos verbais a nível sincrônico, mormente na linguagem popular (janta/ jantar). Diferente, desta forma, de outras propostas que só encaravam os regressivos verbais como bastante produtivos sob um plano diacrônico. 
10 (esp.)

$32-48$

ago.

2020

Said Ali descreveu ainda o processo sob uma perspectiva sincrônica, tomando como base a categoria de gênero em português. Assim se teria:

1. masculinos em -o. Ex.: amparo - atraso;

2. masculinos em -e. Ex.: embarque - combate;

3. femininos em -a. Ex.: amarra - pesca;

4. masculinos e femininos. Ex.: pago/paga, custo/custa. ${ }^{9}$

Semelhantemente a Said Ali, Malkiel (1970) analisou este tipo de deverbal em séries, conforme o gênero apresentado. Este autor, entretanto, foi além dessa análise. Observou, por exemplo, que esses derivados são constituídos, em grande escala, de verbos da $1^{a}$ conjugação, como já havia atentado Nunes (1956) e Maurer Jr. (1959), enquanto os outros tipos de deverbais são formados, em especial, com verbos das outras conjugações. Demais, percebeu que os nomes deverbais regressivos têm, no seu radical, uma forma rizotônica, ${ }^{10}$ diferenciandose, dessa maneira, de outras formas derivadas, como a sufixal, que são preferencialmente arrizotônicas, ou seja, o acento é deslocado da raiz para o radical, acomodando-se assim à tendência paroxitonizante do português.

Em outros termos, enquanto nos sufixais o acento se encontra no morfema, nos regressivos ele está geralmente no lexema (sufocamento/sufoco, sustentação/sustento, destacamento/destaque). Quando à seleção do lugar do acento no lexema do regressivo, ele pode ocorrer tanto na penúltima quanto na antepenúltima sílaba (crítica, desarme). Em vista disso, essa proposta não considera derivados regressivos as formações com nomes atemáticos, a exemplo de matiz (matizar), pedal (pedalar), capim (capinar), função (funcionar).

\footnotetext{
${ }^{9}$ Além dessas formas que apresentam dois regressivos para um mesmo verbo; uma masculina em -o (pago) e outra feminina em -a (paga), é fácil encontrar na nossa língua exemplos de formações que apresentam também dois regressivos para um único verbo, só que alternando -a e -o em -e: derrama/derrame, reclamo/reclame, controlo/controle, desgasto/desgaste, conforto/conforte, decalco/decalque, cuspo/cuspe, conorto/conorte etc. Restaria examinar a diferença semântica entre os dois membros do par, bem como a diferença quanto ao aparecimento das duas formas em português, no sentido de observar qual é a forma mais antiga ou mais vernacular. Há, a este respeito, uma tendência em se acreditar que as formas em -e são de importação estrangeira (cf. HUBER (1986), AGUIAR (1955), NUNES (1956) e MALKIEL (1970)). Este último autor, entretanto, mostra que, nesses casos, há, além de galicismos, arabismos ou ainda formas vernaculares.

${ }^{10}$ Huber (1986) também atentou para essa questão, conquanto o autor tenha tratado as vogais por que terminam os regressivos verbais, conforme já vimos, como sufixos átonos, opostos aos sufixos não acentuados, que seriam, para nós, as verdadeiras formações sufixais.
} 
A questão que se coloca, para essa proposta, é saber como seriam tratados nomes como desdém que, embora seja um nome atemático, apresenta-se como um derivado do verbo, dada a sua natureza abstrata e a possibilidade para uma leitura verbal. Há, para isso, duas explicações: uma de ordem sincrônica e outra de natureza diacrônica. A explicação sincrônica, tal como formulada por Kuri et al. (1981), afirma que a vogal, para esse caso, é zero; o argumento de ordem diacrônica, por outro lado, assinala que desdém teria vindo de uma forma rizotônica do catalão antigo desdeño. Malkiel notou ainda que, entre os deverbais regressivos que apresentam mais de uma forma (custo/custa), podem-se estabelecer diferenças semânticas: a forma masculina parece exprimir, segundo o autor, uma noção mais concreta, enquanto que a feminina carrega uma ideia de ação.

No que respeita à abordagem de Bueno (1958), ela é eminentemente diacrônica. Os regressivos, no entender do autor, só podem ser explicados à luz de um estudo histórico. No par voar/voo, por exemplo, Bueno afirma que da forma latina volare se derivou voar e dele, o substantivo voo. Noutro momento, Bueno (1968), ao lado da sua análise de caráter diacrônico, estabelece um critério para se saber a gênese da formação dos derivados. Vejamos o trecho:

\begin{abstract}
Entre duas formas A e B, pertencentes ao mesmo idioma, devemos preferir como anterior a forma que fôr mais abreviada. Isto porque as formas longas são sempre expansões das mais breves. Assim é erro de muitos dicionários afirmar que jantar veio de jentaculum, ao contrário do verbo jentare é que se fêz o substantivo jentar, jantar e aquêle jentaculum, já no próprio latim, não passava de um diminutivo de jentare. Dentro do próprio português, vg., entre duas formas taramela e tramela, esta é a primitiva e aquela a secundária em que aparece o suarabácti tara em lugar de tra. (BUENO, 1968, p. 23)
\end{abstract}

Mas é na proposta de Barreto e Said Ali que grande parte das gramáticas de língua portuguesa mais recentes pauta suas abordagens. A concepção é ainda de que o processo se baseia na redução da palavra pela ação da analogia decorrente da estrutura da palavra. Por outro lado, a caracterização dos regressivos verbais de acordo com o gênero do substantivo é, entre estes compêndios, um dos modos frequentes de descrever o fenômeno em foco. Bechara (1976, p. 226), por exemplo, define o processo do seguinte modo: "consiste em criar palavras por analogia, através da subtração de algum sufixo, dando a falsa impressão de serem vocábulos derivantes." 
v. 10 (esp.)

$32-48$

ago.

2020

O gramático distribuiu ainda os deverbais em quatro grandes grupos, aos moldes de Said Ali.

Cumpre salientar, no entanto, que Bechara não faz uso do termo derivação regressiva, mas de formação regressiva. Aliás, ele nem mesmo a inclui entre os casos de derivação. Ao invés disso, agrupou-a com outros processos de formação de palavras como a abreviação, a reduplicação e a conversão.

Já Melo (1970), embora seguindo a tradição gramatical, dela se afasta ao tratar dos regressivos verbais indicando pistas de base eminentemente de caráter morfológico para o reconhecimento do percurso derivacional. São suas as palavras:

A maioria dos regressivos são substantivos originados de verbos e, por isso mesmo, designam ação. Não raro, procedem de um mesmo verbo um derivado sufixal e um regressivo, como é o caso de esgotamento e esgote, reclamação e reclamo, escoamento e escôo, bombardeamento e bombardeio, aparelhamento e aparelho. (MELO, 1970, p. 90)

O gramático só deixou de especular sobre as diferenças sintáticas, semânticas e morfológicas que possam existir entre o regressivo e o sufixal de mesma base.

Lima (1989), por sua vez, segue ainda os passos da proposta de Barreto e Said Ali. Diferentemente de Melo, porém, inclui a derivação regressiva dentro dos processos derivacionais de formação de palavras. Esta caracterização se fez com base na presença ou ausência de afixos no radical. Eis como foi feita esta tipologia:

1. Presença de prefixo (derivação prefixal);

2. Presença de sufixo (derivação sufixal);

3. Presença de prefixo e sufixo simultâneos (derivação parassintética);

4. Ausência de afixos (derivação regressiva).

Poderíamos ainda aumentar a lista dos autores que encaram a derivação regressiva verbal como um mero processo subtrativo e analógico, lembrando os nomes de Souza Lima (1937), 
Kuri (1960) $)^{11}$, Coutinho (1976), Cunha (1980) ${ }^{12}$, Luft (1983), entre outros.

Deixemos resumidos, para finalizar este artigo, os principais pontos que foram discutidos nesta seção:

1) Parece haver um consenso em se eleger o verbo como forma básica e o nome como forma derivada. Seja entre aqueles que rotulam o fenômeno como nomes verbais, cuja ideia latente é enxergar, nesses tipos de nomes, sua natureza verbal decorrente do vocábulo que os originou; seja entre os que entendem o processo como substantivos tirados de determinadas pessoas do verbo ou, ainda, entre aqueles que veem, nesses nomes, uma forma reduzida do verbo que lhes deu origem fixando uma associação morfológica e semântica entre nome e verbo ou finalmente entre aqueles que enxergam os derivados regressivos verbais como mais um caso de sufixação;

2) Poucas foram, entre os autores examinados, a indicação de pistas para se reconhecer o derivado e o derivante no processo derivacional, exceção feita a Barreto e a Melo. Barreto apelou para um critério eminentemente semântico, que, se não passar por um exame mais refinado, deixará problemas descritivos sérios. Melo, por seu turno, acenou para um critério de ordem morfológica em que, através de parelhas de derivados de mesma base verbal, pode-se visualizar a direcionalidade do processo que ora se estuda;

3) Não foi ponto pacífico a questão de se saber de que se trata a vogal pela qual termina as formas regressivas verbais. Trata-se de uma vogal temática, desinência e gênero e/ou sufixo? ${ }^{13}$

\footnotetext{
${ }^{11}$ Em Kuri et al (1981), a abordagem para os regressivos verbais é diferente. A derivação deverbal ou pós-verbal, como é cognominada pelos autores, é descrita como um processo derivacional em que não se faz uso de sufixos, mas apenas de vogais temáticas $\mathbf{- a},-\mathbf{- e},-\mathbf{- o}$, formando-se, a partir de bases verbais, substantivos de ação, sem com isso haver oposição de gênero. Observe-se, por esta última informação, que a tipificação dos deverbais já não é feita levando-se em conta a diferença de gênero, como a proposta por Said Ali. Aqui também não se fez referência ao critério de Barreto. É reconhecida, porém, a dificuldade de se distinguir primitivo de derivado, mas o procedimento utilizado para essa distinção é feita através de uma lista com 116 substantivos deverbais que os autores julgam ser os mais comuns. Em outras palavras, para se reconhecer o que é primitivo e o que é derivado nesta proposta, deve-se recorrer à memória ou então à lista com os deverbais arrolados.

${ }^{12}$ Cunha e Cintra (1985), ainda que repitam as mesmas ideias de Cunha (1980), chamam a atenção para o fato de que, a par do critério prático para a distinção da direcionalidade do processo, proposto por Barreto, há outro, de extração gerativista. Os autores mostram, em nota marginal, que Basílio não considera relevante a origem de base, mas a relação geral entre nome e verbo. Esta relação seguirá, em princípio, a um padrão derivacional que poderia ser formalizado da seguinte maneira: $[\mathrm{x}]_{\mathrm{V}} \rightarrow[\mathrm{x}]_{\mathrm{V}} \rightarrow\left[\mathrm{x}^{\prime}\right]_{\mathrm{N}}$. Onde data a existência de um verbo em português, é possível prever uma relação lexical entre este verbo e um nome x'. É mostrado ainda que, segundo Basílio, esse padrão derivacional pode abranger o fato de haver nos verbos, muitas vezes, uma relação com nomes morfologicamente básicos, e não somente nomes deverbais.

13 Para aumentar a diversidade de opiniões, Meillet e Vendryès (1960) consideram todo o conjugado (radical + vogal) como raiz, chamando esses nomes de nomes-raiz.
} 
10 (esp.)

$32-48$

ago.

2020

4) Houve divergência, entre os autores que privilegiaram a diacronia para o estudo da derivação regressiva verbal, em se descobrir se esses regressivos vêm diretamente do radical puro do verbo ou tirados das pessoas verbais;

5) Não foram, por fim, considerados aspectos suprassegmentais para a análise dos deverbais regressivos, como a mudança acentual ou metafonia (sufocar/sufoco), e o próprio deslocamento de acento (denunciar/denúncia).

\section{Considerações finais}

Como vimos, o propósito deste artigo foi o de discutir a derivação regressiva verbal na tradição filológico-gramatical.

Observando a organização geral do artigo, pôde-se verificar que a pesquisa trata de um estudo de síntese. E esta realmente foi a nossa meta maior: proceder a uma revisão teórico-crítica sobre a derivação regressiva verbal em língua portuguesa, sem nos importar, neste instante, com uma análise empírica fundada no exame de um corpus definido.

Não quisemos, portanto, propor novas técnicas e métodos capazes de analisar e descrever o processo em tela, mas antes, como já foi enfatizado, fazer considerações teóricas a partir dos modelos já existentes, a fim de prover uma sistematização crítica e coerente sobre o assunto.

Face a tudo isso, não podemos, portanto, estar em concordância perfeita com o ditado latino que afirma theoriae volant, exempla manet, pois, só mediante a teoria transcendemos a singularidade e a imediatez dos dados.

\section{Referências}

AGUIAR, M. de. Notas de português de Filinto e Odorico (transcrição e comentário). Rio de Janeiro: Organização Simões, 1955.

Repasse crítico da gramática portuguesa. Fortaleza: Casa José de Alencar/Programa Editorial, 1996.

AKELE, D. O fenômeno da derivação regressiva: uma abordagem tradicional e gerativa. SIGNO: FISK, Santa Cruz do Sul, v. 13, n. 19, p. 5-28, 1988.

AZEVEDO FILHO, L. A. de. Para uma gramática estrutural da língua portuguesa. Rio de Janeiro: Gernasa, 1971. 
BARRETO, M. Novíssimos estudos de língua portuguesa. Rio de Janeiro: Presença, 1980.

De gramática e de linguagem. Rio de Janeiro: Presença, 1982.

BARROS. J. de. Gramática da língua portuguesa. Lisboa: sem editora, 1957.

BASÍLIO, M. Estruturas lexicais do português: uma abordagem gerativa. Petrópolis: Vozes, 1980.

Teoria lexical. São Paulo: Ática, 1991.

BECHARA, E. Moderna gramática portuguesa. São Paulo: Companhia Editora Nacional, 1976.

BLOOMFIELD, L. Language. London: The University of Chicago Press, 1984.

BUENO, F. da S. Pequena gramática. Rio de Janeiro: Edição Rio, 1958.

A formação histórica da língua portuguesa. São Paulo: Saraiva, 1968.

CAMARA JR., J. M. Dicionário de linguística e gramática. Petrópolis: Vozes, 1981.

COUTINHO, I. de L. Gramática histórica. Rio de Janeiro: Ao Livro Técnico, 1976.

CUNHA, C. F. da. Gramática da língua portuguesa. Rio de Janeiro: FENAME, 1980.

CUNHA, C. F. da; CINTRA, L. Nova gramática do português contemporâneo. Rio de Janeiro: Nova Fronteira, 1985.

GAMARSKI, L. A derivação regressiva: um estudo da produtividade lexical em português. Goiânia: CEGRAF, 1988.

GOMES, A. Gramática portuguesa. Rio de Janeiro: Francisco Alves e Cia, 1913.

HOCKETT, C. F. A course in modern linguistics. USA: Macmillan, 1958.

HUBER, J. Gramática do português. Lisboa: Calouste Gulbenkian, 1986.

KEHDI, V. Os deverbais regressivos em português. São Paulo: Anais dos Seminários do XXX do GEL, 1995. p. 421- 425.

JUCÁ FILHO, C. Gramática histórica do português. Rio de Janeiro: EPASA, 1945.

KURI, A. da G. Pequena Gramática. Rio de Janeiro: Agir, 1960.

KURI, A. da G. et al. Gramática objetiva da língua portuguesa I: fonologia, ortografia, morfologia. Rio de Janeiro: Edição Rio, 1981.

LIMA, R. Gramática normativa da língua portuguesa. Rio de Janeiro: José Olympio, 1989.

LOBATO, L. Sintaxe gerativa do português: da teoria padrão à teoria da regência e ligação. Belo Horizonte: Vigília, 1995. 
10 (esp.)

$32-48$

ago.

2020

LUFT, C. P. Moderna gramática brasileira. Rio de Janeiro: MEC/FENAME, 1983.

MACIEL, M. Grammatica descriptiva. Rio de Janeiro: Livraria Francisco Alves, 1910.

MALKIEL, Y. Genetic analysis of words formation. In: SEBEOK, T. A. (Ed.) Current trend in linguistics. vol. 3. Theoretical foundations. The Hague/Paris: Mouton, 1970. p. 305-364.

MAURER JR, T. H. Gramática do latim vulgar. Rio de Janeiro: Livraria Acadêmica, 1959.

MELO, G. C. de. Gramática fundamental da língua portuguesa. Rio de Janeiro: Livraria Acadêmica, 1970.

MEYER-LÜBKE, W. Grammaire des langues romane: t. deux: morphologie. Paris: G. E. Stechert, 1923.

MEILLET, A; VENDRYÈS, J. Traité de grammaire comparé des langues classiques. Paris: Libraire Ancienne Honoré Champion, 1960.

MICHAËLIS VASCONCELOS, C. Lições de filologia portuguesa. Lisboa: Martins Fontes, s/d.

MONTEIRO J. L. O morfema zero no processo de derivação. Revista de Letras, Fortaleza, v. 1, n. 2, p. 95-113, 1978.

Morfologia portuguesa. São Paulo: Pontes, 1986.

NUNES, J. J. Compêndio de gramática histórica: fonética e morfologia. Lisboa: Livraria Clássica, 1956.

OLIVEIRA, F. Gramática da linguagem portuguesa. Lisboa: Imprensa Nacional/ Casa da Moeda, 1975.

PEI, M. A.; GAYNOR, F. A Dictionary of linguistics. London: Peter Owen, 1965.

PEREIRA, E. C. Gramática expositiva. São Paulo: Companhia Editora Nacional, 1958.

PIDAL, R. M. Manual de gramática histórica española. Madrid: Espasa-Calpe, 1958.

RIBEIRO, J. Grammatica portugueza. Rio de Janeiro: Francisco Alves e Cia, 1911.

RIBEIRO, J. Grammatica portugueza. Rio de Janeiro: Francisco Alves e Cia, 1933.

SAID ALI, M. Gramática histórica portuguesa. São Paulo: Edições Melhoramentos, 1964.

SILVA JÚNIOR, P.; ANDRADE, L. Grammatica da língua portugueza. São Paulo: Livraria Clássica, 1894.

SOUZA LIMA, M. P. de Gramática expositiva de língua portuguesa. São Paulo: Livraria Clássica, 1937. 